\title{
DePEGylation Studies: PEG-RBC Stability in Conditions Consistent with Massive Transfusion
}

\author{
M SCOTT MOORE, ERIC OKELBERRY, KRYSTLE CORDINGLEY, \\ ALEX DRAKE, ZACHARY ROBINETT
}

\begin{abstract}
Each year the United States population receives an estimated 12 to 14 million units of packed red blood cells (RBCs) and whole blood. ${ }^{1,2}$ It is estimated that $33 \%$ of transfusions associated with trauma are with unmatched type O RBCs (UORBC). ${ }^{3}$ UORBCs have been proven effective and relatively safe ${ }^{3}$ however, by masking RBC surface antigens the risk of transfusion reaction may be further decreased. It is, therefore, important to evaluate and validate the stability of antigen masked RBCs, which may play a part in avoiding transfusion reactions. These antigen-masked RBCs would be regularly subjected to abnormal in vivo conditions commonly associated with massive transfusion such as lactic acidosis, bacteremia, and in vitro irradiation, which is frequently used to sterilize and decrease T Lymphocyte counts in RBC units before transfusion. This study compared two methods of masking RBC antigens by PEGylation: maleimidePEGylation and cyanuric chloride-PEGylation. RBC PEGylation effectively masks the $\mathrm{Rh}(\mathrm{D})$ antigen $^{4,5}$ and PEG-RBC bond stability was evaluated by comparison of pre and post exposure agglutination with anti-D sera. While the stability of maleimide-PEG-RBCs remained unaffected, the cyanuric chloride-PEG-RBCs remained stable in the bacteremia and irradiation studies, but critical concentrations of lactic acid caused dePEGylation. Further studies are warranted to ensure in vivo stability.
\end{abstract}

INDEX TERMS: Pegylation, Erythrocytes, Transfusion, Polyethylene Glycol (PEG), Antigen Masking

Clin Lab Sci 2011;24(4):227

M Scott Moore, Weber State University, Department of Clinical Laboratory Sciences, Ogden, Utah
Eric Okelberry, Weber State University, Department of Clinical Laboratory Sciences, Ogden, Utah

Krystle Cordingley, Weber State University, Department of Clinical Laboratory Sciences, Ogden, Utah

Alex Drake, Weber State University, Department of Clinical Laboratory Sciences, Ogden, Utah

Zachary Robinett, Weber State University, Department of Clinical Laboratory Sciences, Ogden, Utah

Address for Correspondence: Scott Moore, $6610 \mathrm{~W}$ Laurel Ave, Glendale $A Z$ 85304, (623) 688-2131, scott.moore@azwebmail.midwestern.edu

\section{INTRODUCTION}

Many attempts have been made to create antigenmasked RBCs for transfusion, the most promising of which is PEGylation of RBC antigens. ${ }^{5,6}$ By attaching long polymer chains of polyethylene glycol (PEG) to $\mathrm{RBC}$ membranes, researchers have created a product whereon RBC surface antigens remain undetected by recipient antibodies. ${ }^{5}$ PEG-RBCs have been shown to remain fully functional in $\mathrm{O}_{2}$ transport, $\mathrm{pH}$ buffering capacity, and clearance from the body. Furthermore, PEGylated blood products may enhance peripheral circulation and PEGylation of residual lymphocytes in transfused RBC units may decrease the possibility of graft vs. host disease. ${ }^{7}$ Due to their potential utility, PEG-RBCs could provide a supplement to the current blood supply, yield an alternative for transfusion recipients with multiple abnormal antibodies, and could be immediately administered in cases of urgent transfusion. ${ }^{8}$ Trauma, which may be complicated by septicemia or acidosis, may be an indication for emergent administration of PEG-RBC; such conditions may induce instability in the PEG-RBC bond. Patients in shock commonly present with lactic acidosis due to 


\section{RESEARCH AND REPORTS}

hypoperfusion. ${ }^{9}$ Traumatic injuries and many lifesaving procedures increase the risk of bacterial infection, ${ }^{10,11,12}$ the subsequent bacteremia may weaken the PEG-RBC bond due to bacterial byproducts that decrease blood $\mathrm{pH}$ or the enzymatic catabolization of PEG. ${ }^{13}$ As dePEGylation ensues, donor RBC surface antigens would be exposed to host antibodies and hemolytic transfusion reaction could occur. Many, but not all RBC units undergo pre-transfusion irradiation, ${ }^{14}$ which may also hydrolyze the PEG-RBC bond.

Two PEGylation methods were also compared to distinguish the most stable product in various conditions: these were maleimide-PEGylation and cyanuric chloride PEGylation. PEGylation effectively masks the $\mathrm{Rh}(\mathrm{D})$ antigen, ${ }^{5,6}$ therefore by quantifying agglutination reactions with anti-D sera before, during and after subjecting the PEGylated RBCs to each simulated condition above, a standardized determination of dePEGylation can be established.

\section{MATERIALS AND METHODS}

One unit of type $\mathrm{O} R \mathrm{Rh}(\mathrm{D})$ positive whole blood was drawn according to current standards by a licensed phlebotomist in a blood donation center where the plasma was also expressed. The unit of packed RBCs was immediately shipped to the laboratory of Dr. Parimala Nacharaju where it was split into thirds and PEGylated. PEGylation is the addition of polyethylene glycol to the protein amino terminals on the RBC membrane. One third of the RBCs were derivatized by maleimide-PEG-5000 (Laysan Biological) in the presence of 2-iminothiolane for 2 hours in incubation buffer, washed three times and incubated again as previously described. ${ }^{15}$ The second portion was derivatized by cyanuric-PEG-5000 (Sigma-Aldrich), incubated for one hour and subsequently washed twice. ${ }^{16}$ The third portion was kept as a control. The derivatized and control RBCs were received three days after initial shipment and the maleimide-PEG-RBCs, cyanuric PEG-RBCs, and control RBCs were each assayed (as described below) 10 times in order to determine a baseline value of agglutination with which to compare all other results. All testing was completed within 30 hours after the blood was received so that minimal aberrant results due to sample degradation or RBC metabolism were observed.
Each of these samples was separated and used to simulate each of the abnormal in vitro conditions; 9 tubes were used for each reaction, 3 separate $3 \mathrm{~mL}$ aliquots of all 3 RBC types were placed into red top Vacutainer $^{\circ}$ tubes, where the abnormal in vitro conditions were created; lactic acidosis and septicemia (Figure 1). Prior to separation, $25 \mathrm{~mL}$ samples of each $\mathrm{RBC}$ type were irradiated with $25 \mathrm{Gray}^{17}$ according to current standards.

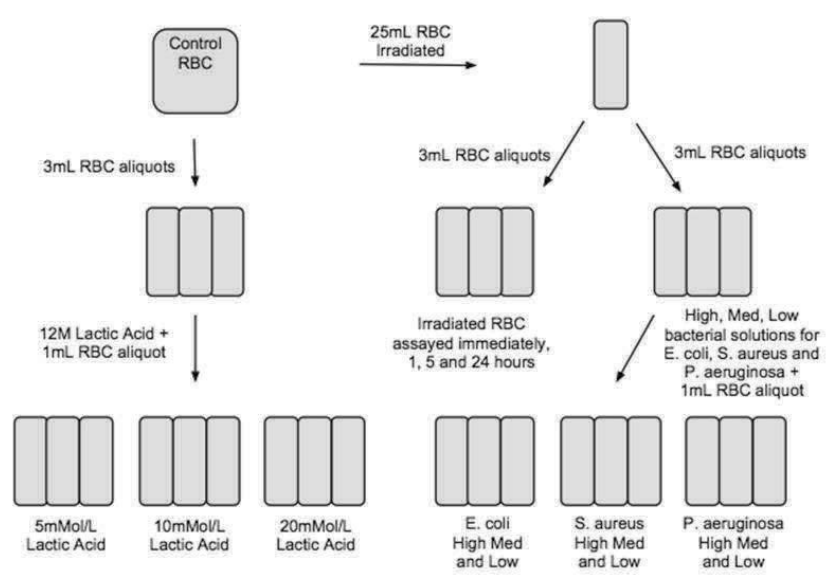

Figure 1: Example flow diagram for control RBCs. This process was repeated for both the Maleimide PEGylated RBCs and Cyanuric PEGylated RBCs.

\section{Lactic Acidosis}

Twleve M lactic acid was diluted with Phosphate Buffered Saline (PBS) and added to all nine of the $3 \mathrm{~mL}$ aliquots to simulate low $(5 \mathrm{mMol} / \mathrm{L})$, medium $(10 \mathrm{mMol} / \mathrm{L})$, and high $(20 \mathrm{mMol} / \mathrm{L})$ concentrations in each RBC type. Each tube was assayed initially, and at 30 minutes, 1 hour and 5 hours; serum lactate levels were measured by the enzymatic LDH method with spectrophotometric detection (Cobas chemistry analyzer, Roche Diagnostics) at each interval to track increases in lactate caused by RBC metabolism.

\section{Irradiation}

Three $\mathrm{mL}$ aliquots of each RBC type that had been irradiated were placed in three separate tubes. Extent of dePEGylation was assessed subsequently, at 1,5 and 24 hours. The remainder of the irradiated blood was then used for the bacterial portion of the study to ensure complete sterility of the RBCs.

\section{Bacteremia}

All three types of irradiated RBCs were immediately cultured on a blood agar plate under aerobic conditions 


\section{RESEARCH AND REPORTS}

at $37^{\circ} \mathrm{C}$ in triplicate to ensure initial sterility; no initial irradiated plates exhibited bacterial growth. After initial sterility was confirmed, strains of $P$. aeruginosa, $S$. aureus and E. coli were diluted to low, medium, and high concentrations separately in Phosphate Buffered Saline (PBS) to create 3 bacterial solutions for each species: low $(1,000 \mathrm{CFU} / \mathrm{mL})$, medium $(10,000$ $\mathrm{CFU} / \mathrm{mL})$ and high $(100,000 \mathrm{CFU} / \mathrm{mL})$. One $\mathrm{mL}$ of Control RBCs was added to $500 \mathrm{uL}$ of the high, medium, and low concentrations of $S$. aureus. This pattern was followed for E. coli and P. aeruginosa as well resulting in 9 samples of control RBCs (Figure 1). Cyanuric PEG-RBCs and maleimide PEG-RBCs were also tested according to the same pattern. Each tube was then assayed initially, at 24, 48 and 72 hours: $1 \mathrm{uL}$ of each solution was cultured on a blood agar plate and colonies were counted in $\mathrm{CFU} / \mathrm{mL}$.

\section{Assay}

To evaluate any change in PEGylation, microscopic agglutination reactions were graded, in quadruplicate, on a hemocytometer for each RBC type and each simulated condition. This protocol used for the agglutination reactions was the same for every assay performed in the study. As anti-D sera is added to $\mathrm{Rh}(\mathrm{D}) \mathrm{RBCs}$, the antibodies are able to disrupt the RBC membrane which allows trypan blue inside the cell providing visualization and quantification of $\mathrm{RBC}$ membrane destruction.

For each tube, a $500 \mathrm{uL}$ aliquot of a $6 \%$ hematocrit solution was added to $500 \mathrm{uL}$ of a $1: 3$ anti-D sera (Ortho) to PBS solution and centrifuged. The centrifugate was poured off and $10 \mathrm{uL}$ of the resulting RBC button were pipetted into a separate tube along with $10 \mathrm{uL}$ of trypan blue, which only stains RBCs lacking an intact membrane and indicates a nonviable cell, ${ }^{18}$ and $2.5 \mathrm{~mL}$ of PBS were added to each of 4 separate test tubes for testing in quadruplicate. $15 \mathrm{uL}$ of the resulting $\mathrm{PBS} /$ trypan blue/RBC solution from each of the 4 tubes were loaded into separate hemocytometer for counting. Five RBC squares were counted in every hemocytometer reading (on average 239 RBCs were counted per five RBC squares). RBCs were counted to determine a ratio of viable (non-agglutinated and unstained) to total RBCs counted. Thus, a decrease in this ratio that did not occur simultaneously in the control RBCs would indicate dePEGylation.
Baseline control values were obtained before subjecting any of the RBCs to the simulated conditions. 10 aliquots from each blood type were assayed in quadruplicate and an average ratio of unstained to total RBCs was determined for each RBC type. Graphically, these values represented a normal distribution and $\mathrm{a}+/$ 2 standard deviation range was determined. If values remained within this range throughout the course of testing each condition, it was assumed that no significant dePEGylation had occurred. Any decrease in viability 2 SD away from the mean was assumed to be dePEGylation, and there was no observed increase in viability; such variability above the mean could be caused by mistakenly counting non-viable RBCs as viable due to cell overlap on the hemocytometer.

More control RBCs were subjected to the high and low extremes of each condition and the same amount of solution was counted on a hemocytometer without adding anti-D reagent to further ensure that increased levels of agglutination were not a result of each condition's effect on the natural RBC.

\section{RESULTS}

Each PEG-RBC type was assayed, the ratios of viable:total RBCs were plotted and the mean value was set as the baseline. The term "did not deviate significantly from the mean" will be used to denote that the values obtained from each assay remained within the predetermined 2 standard deviation range which was calculated individually for each RBC type, indicating that dePEGylation did not occur. (Table 1)

\section{Irradiation}

DePEGylation was not observed in either maleimidePEG or cyanuric-PEG as the ratios of viable cells:total RBCs did not deviate more than 2SD from the mean.

Table 1. Baseline ratio of unstained cells to total cells

Maleimide-PEG Cyanuric-PEG Control RBC

\begin{tabular}{lrcc} 
Baseline Ratio & .9847 & .9864 & .2868 \\
+/- 2 SD Range & $.9480-1.000$ & $.9502-1.000$ & $.2255-.3101$ \\
\hline
\end{tabular}

\section{Bacteremia}

Table 2: Ranges of bacterial counts (in 1,000 CFU/mL units); at all time intervals, ranges indicate the highest 


\section{RESEARCH AND REPORTS}

and lowest values seen in all RBC types and in all three species combined. Values from bacteremia assays for both maleimide-PEG and cyanuric-PEG did not deviate significantly from the mean and dePEGylation was not observed after exposure to low, medium, and high $\mathrm{CFU} / \mathrm{mL}$ concentrations. (Table 2)

\begin{tabular}{|c|c|c|}
\hline $\begin{array}{l}\text { Relative Bacterial } \\
\text { Concentration }\end{array}$ & Time & $\begin{array}{l}\text { Range of Bacterial Counts of } \\
500 \mathrm{uL} \text { bacterial solution and } \\
\text { blood aliquot } \times 1000 \mathrm{CFU} / \mathrm{mL}\end{array}$ \\
\hline Low & Initial & $<2$ \\
\hline Low & 24 Hours & $3-10$ \\
\hline Low & 72 Hours & $89-126$ \\
\hline Medium & Initial & $3-7$ \\
\hline Medium & 24 Hours & $25-37$ \\
\hline Medium & 72 Hours & $110-165$ \\
\hline High & Initial & $60-80$ \\
\hline High & 24 Hours & $100-138$ \\
\hline High & 72 Hours & $>200$ \\
\hline
\end{tabular}

\section{Lactic Acidosis}

Maleimide-PEG values did not deviate significantly from the mean during the lactic acid study.

Figure 2 is a comparison of maleimide and cyanuricPEG in lactic acid study. While maleimide-PEG-RBCs were not significantly affected by increased levels of lactic acid, dePEGylation of cyanuric-PEG-RBCs began at a serum lactic acid value between 11.2 - 14.6 $\mathrm{mMol} / \mathrm{L}(p<0.0013)$. The dashed line shows the lower boundary of the range of significance.

\section{Cyanuric-PEG $5 \mathrm{mMol} / \mathrm{L}$}

At 5 hours, significant dePEGylation occurred decreasing the ratio value to .941 ; this indicates a decrease of $1.01 \%$ of PEGylated cells. A serum lactic acid level of $14.8 \mathrm{mMol} / \mathrm{L}$ was measured at this time using the $\mathrm{LDH}$ method.

\section{Cyanuric-PEG $10 \mathrm{mMol} / \mathrm{L}$}

Ratio values of .9039 and .7900 were recorded at 1 hour and 5 hours respectively for a total of $16.1 \%$ dePEGylation. Serum lactic acid levels of $14.6 \mathrm{mMol} / \mathrm{L}$ and $17.4 \mathrm{mMol} / \mathrm{L}$ were measured at the same times using the previously described enzymatic $\mathrm{LDH}$ spectrophotometric method.

\section{Cyanuric-PEG $20 \mathrm{mMol} / \mathrm{L}$}

DePEGylation immediately occurred upon adding the dilute lactic acid, the viable to total $\mathrm{RBC}$ ratio was significantly lower than the mean at $.8460 ; 32.7 \%$ dePEGylation had occurred at 5 hours. Serum lactic acid levels above $20 \mathrm{mMol} / \mathrm{L}$ are considered higher than critical clinical ranges of significance and were not measured.

\section{DISCUSSION}

The consistency in results obtained from every assay of control RBCs verified that any decrease in PEG-RBC viability throughout the experiment was the result of dePEGylation, and not an artifact caused by alteration to the RBC or antibody.

Pre-transfusion radiation of all RBC types was not observed to increase agglutination, which indicates that both PEGylation methods can withstand standard radiation procedures without dePEGylation. CyanuricPEG was dePEGylated at a serum lactic acid level between 11.4 and $14.6 \mathrm{mMol} / \mathrm{L}$ which is very significant given that in vivo serum lactic acid levels above $4 \mathrm{mmol} / \mathrm{L}$ are associated with $11 \%$ survival in ICU patients if persistent for 24 hours, and the potential complications of a hemolytic transfusion reaction superimposed on severe lactic acidosis would most likely ensure death. ${ }^{19}$ Thus, cyanuric-PEG-RBCs are not plausible RBCs in such situations. The lack of reactivity of the remaining results however is encouraging. The maleimide-PEG-RBCs continued to mask the $\mathrm{Rh}(\mathrm{D})$ antigen in all simulated conditions.

\section{CONCLUSION}

While not confirmatory, this pilot study serves to encourage further testing of PEG-RBCs as a possible method of creating functional antigen-masked RBCs. While masking of the $\mathrm{Rh}(\mathrm{D})$ antigen was accomplished in this study, greater utility would be achieved by successful masking of $\mathrm{ABO}$ antigens. Testing of only one unit of blood may not accurately represent the entire population and further studies with multiple donors are warranted. The maleimide method of PEGylation demonstrated superior durability in lactic acidosis and should therefore be incorporated into the focus of further studies while the cyanuric method should be re-evaluated. Furthermore, these findings suggest the need to evaluate the stability of PEG-RBCs in a plethora of potential in vivo complications given that in vitro dePEGylation has occurred. 

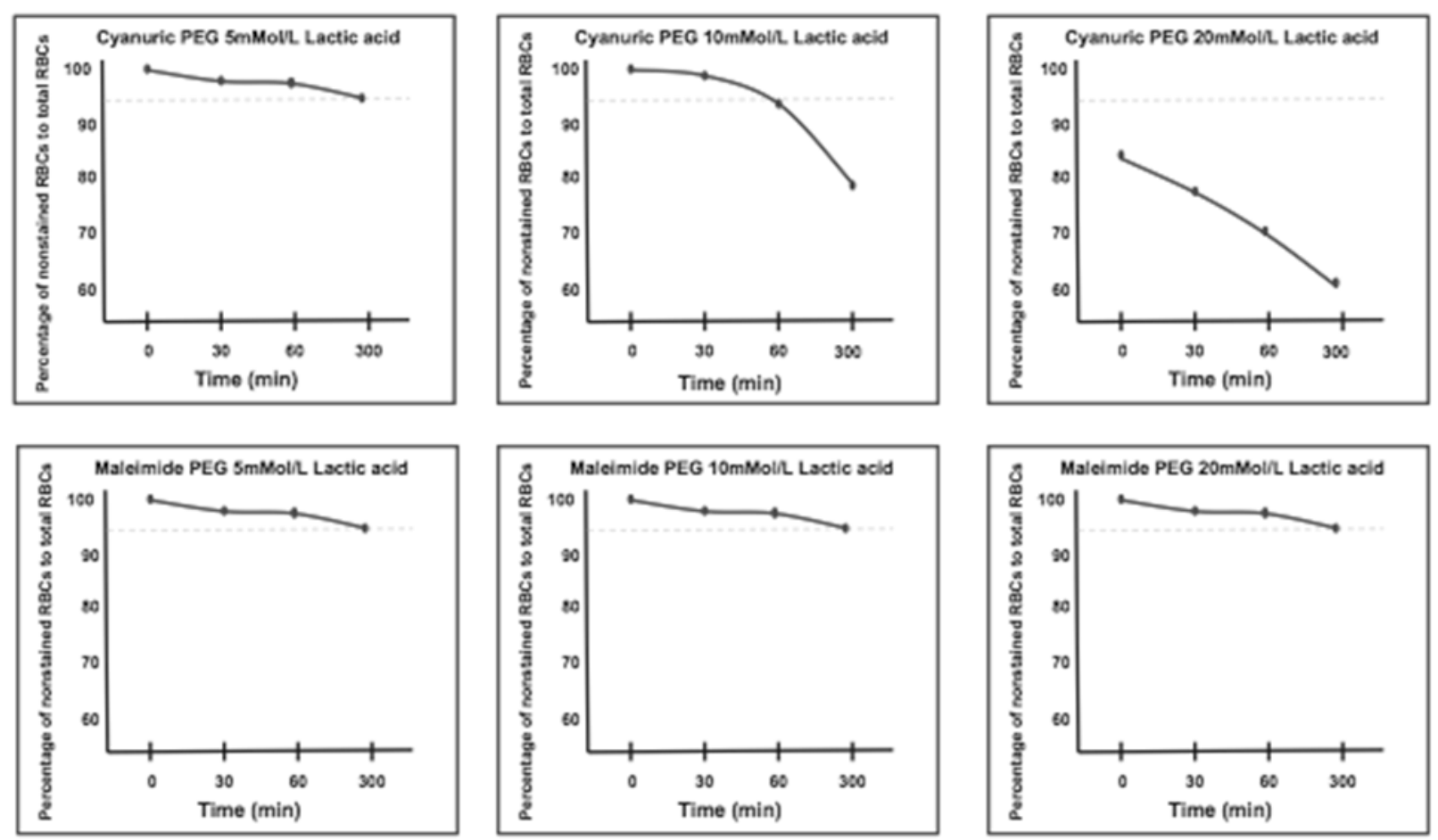

Figure 2. Tracks the percentage of viable PEG-RBC to total cells counted per assay subjected to differing mMol/L concentrations of lactic acid; the $94.82 \%$ (Maleimide) and $95.02 \%(\mathrm{CNCl})$ lines show the determined 2 S.D. range; a drop below this value indicates significant dePEGylation. Maleimide-PEG was not affected while cyanuric-PEG was significantly dePEGylated by the high lactate concentration $(\mathrm{p}<0.0013)$.

in a plethora of potential in vivo complications given that in vitro dePEGylation has occurred.

ACKNOWLEDGEMENTS: We would especially like to thank Dr. Parimala Nacharaju at the Albert Einstein School of Medicine, for all of her time and advice that she offered. We would also like to thank our faculty mentor Kara Hansen-Suchy, the Clinical Laboratory Sciences faculty and the Weber State University Office of Undergraduate Research for the funding and support of this project.

\section{REFERENCES}

1. EC Vamvakast, HF Taswell. Epidemiology of blood transfusion. Transfusion. 1994;34(6):464-70.

2. US Census Bureau Population Estimates. http://www.census. gov/popest/states/NST-ann-est.html. Accessibility verified March 10, 2011.

3. Dutton R, Shih D, Edelman B, Hess J, Scalea T. Safety of uncrossmatched type-O red cells for resuscitation from hemorrhagic shock. J Trauma. 2005;59(6):1445-9.

4. Mark S, Murad K, Koumpouras F, Talbot M, Eaton J. Chemical camouflage of antigenic determinants: stealth erythrocytes. Proc Natl Acad Sci. 1997;94:7566-71.

5. Murad K, Mahany K, Brugnara C, and others. Structural and functional consequences of antigenic modulation of red blood cells with methoxypoly(ethylene glycol). J Blood. 1999;93: 2121-7.

6. Abuchowski A, van Es T, Palczuk N, Davis F. Alteration of immunological properties of bovine serum albumin by covalent attachment of polyethylene glycol. J Biol Chem. 1977:357881.

7. Jang J, Lee D, Park S, Byun Y. Immune reactions of lymphocytes and macrophages against PEG grafted pancreatic islets. Biomaterials 25. 2004:3663-9.

8. Institute of Medicine HIV and the Blood Supply: An Analysis if Crisis Decision Making, Institute of Medicine Report (Natl. Acad. Press, Washington, DC). 1996.

9. Chameides L, Hazinski MF, eds. American Heart Association. Pediatric Advanced Life Support. 1997.

10. Goetz A, Wagener M, Miller J, Mudder R. Risk of infection of ventral venous catheters: effect of site of placement and catheter type. Infect Control Hosp Epidemiol 1998;19(11):842-5.

11. Reduction in central line associated blood stream infections among patients in intensive care units. MMWR Morb Mortal Wkly Rep 2005;54(40):1013-6.

12. Centers for Disease Control. Central line associated blood stream infections (CLABSI) event. http://www.cdc.gov/nhsn/ pdfs/pscmanual/4psc_clabscurrent.pdf Accessibility verified December 24, 2010.

13. Haines J.R., Alexander M. Microbial degradation of polyethylene glycols. Applied Environmental Microbiology. 1975;29:621-5.

14. Guidelines for irradiation of blood and blood components. New York State Council on Human Blood and Transfusion 


\section{RESEARCH AND REPORTS}

Services. 2 ed 2004. Accessibility verified March 10, 2011 http://www.wadsworth.org/labcert/blood_tissue/irradgdlnsfinal 1204.pdf.

15. Nacharaju P, Manjula B, Acharya S. Thiolation mediated pegylation platform to generate functional universal red blood cells. Artif Cells Blood Substit Immobil Biotechnol 2007; 35:107-18.

16. Sabolovic D, Sestier C, Perrotin P, Guillet R, Tefit M, Boynard M. Covalent binding of polyethylene glycol to the surface of red blood cells as detected and followed up by cell electrophoresis and rheological methods. Electrophoresis. 2000;21(2):301-6.

17. Pelszynski M, Moroff G, Luban N, Taylor B, Quinones M. Effect of $\gamma$ irradiation of red blood cell units on T-cell inactivation as assessed by limiting dilution analysis: implications for preventing transfusion-associated graft-versushost disease. Blood. 1994;83(6):1683-8.

18. Strober W. Trypan blue exclusion test of cell viability. Current Protocols in Immunology. 1997:Appendix A.3B.1.

19. Stackpoole P, Zorovich B, et al. Natural history and course of acquired lactic acidosis in adults. Amer J Med. 1994;97(1):4754.

20. Scott M, Bradley A, Murad K, Camouflaged blood cells: lowtechnology bioengineering for transfusion medicine. Transfusion Medicine Reviews. 2000;14:51-3.
21. Chen PC, Huang W, Stassinopoulos A, Cheung AT. Effects of PEGylated hamster red blood cells on microcirculation. Artif Cells Blood Substit Immobil Biotechnol 2008;36(4):295-309.

22. Kaplan L, Frangos S. Clinical review: Acid-base abnormalities in the intensive care unit-part II. Critical Care Forum. 2005;9:2.

23. Yousef H. M, Padmore R.F, Neurath D.D, Rock G.A. The effect of patient-controlled analgesia on co-administered red blood cells. Transfusion. 2006;46:372-6.

24. Sarvi F, Vasheghani-Farahani E, Shojaosadati S.A., and others. Surface treatment of red blood cells with monomethoxypolyethylene glycol activated by succinimidyl carbonate. Iranian Polymer Journal. 2006;15:525-4.

25. Anderson S, Cockrayne S. Clinical chemistry concepts and applications. Waveland Press Inc. 2003:425-44.

26. Robinette Z, Moore M, Okleberry E, Drake A, Cordingley K. DePEGylation studies: PEG RBC durability in conditions consistent with transfusion. Poster Presentation at National Conferences of Undergraduate Research 2009.

27. EC Vamvakast, HF Taswell. Epidemiology of blood transfusion. Transfusion. 1994;34(6):464-70.

28. US Census Bureau Population Estimates. http://www.census. gov/popest/states/NST-ann-est.html. Accessibility verified March 10, 2011.

The peer-reviewed Research and Reports Section seeks to publish reports of original research related to the clinical laboratory or one or more subspecialties, as well as information on important clinical laboratory-related topics such as technological, clinical, and experimental advances and innovations. Literature reviews are also included. Direct all inquiries to David $L$ McGlasson MS, MLS, 59th Clinical Research Division/SGRL, 2200Berquist Dr., Bldg. 4430, Lackland AFB TX 782369908, david.mcglasson@lackland.af.mil

Clinical Laboratory Science encourages readers to respond with thoughts, questions, or comments regarding these articles. Email responses towestminsterpublishers@comcast.net.In the subject line, please type the journal issue and lead author such as "CLIN LAB SCI 24(4) RE MOORE". Selected responses may appear in the Dialogue and Discussion section in a future issue. Responses may be edited for length and clarity. We look forward to hearing from you. 